\title{
O CONTRATUALISMO NA DISPUTA PELA LEGITIMIDADE DA ORIGEM DO INSTINTO HUMANO: OS ASSENTAMENTOS MATERIAIS DA MORAL EM CHARLES R. DARWIN
}

\author{
Alan Júnior dos Santos ${ }^{\prime}$
}

\begin{abstract}
RESUMO: Em contraposição à teoria contratualista, principalmente a linha hobbesiana, da origem das sociedades organizadas e das faculdades morais, Darwin lança um novo olhar sobre as formas elementares do convívio primitivo em Descent of man (1871). Darwin ponderou que o ser humano não ocupa um espaço privilegiado no mundo vivo, afirmando que a definição da condição humana como portador de características de sociabilidade e criação de caracteres simbóliços de significados, são um dado possibilitado por transformações que o Homo Sapiens passou dentro de uma variedade de espécie em contato com outras formas de variedades. Porém este novo olhar é ofuscado por sua obra anterior de mais destaque, Sobre a Origem das Espécies (1859), que embora não aplique suas conclusões sobre a organização social do homem, é assim interpretada pelas ciências humanas ocidentais oitocentistas. Este artigo tem por objetivo discutir a concepção que Darwin levantou sobre a moral e sua constituição a partir de processos biológicos em contraposição à teoria contratualista clássica, e a partir disto entender porque sua segunda obra de maior relevância foi ofuscada por quase um século retornando aos holofotes somente a partir da década de 1980.
\end{abstract}

Palavras-Chave: Darwin; Moral; Contratualismo.

\section{CONTRATUALISM IN THE DISPUTE OF THE LEGITIMACY OF THE ORIGIN OF THE HUMAN INSTINCT: THE MATERIAL SETTINGS OF MORAL IN CHARLES R. DARWIN}

\begin{abstract}
In contrast to the contractualist theory, mainly the Hobbesian line, of the origin of the organized societies and the moral faculties, Darwin throws a new look on the elementary forms of the primitive conviviality in Descent of man (1871). Darwin pondered that the human being does not occupy a privileged space in the living world, affirming that the definition of the human condition as bearer of characteristics of sociability and creation of symbolic characters of meanings, are given by transformations that Homo Sapiens passed within a variety of species in contact with other forms of varieties. But this new look is overshadowed by his earlier work, On the Origin of Species (1859), which, although it does not apply its conclusions about the social organization of man, is thus interpreted by the nineteenth-century Western human sciences. This article aims to discuss Darwin's conception of morality and its constitution from biological processes in contrast to classical contractualist
\end{abstract}

\footnotetext{
${ }^{1}$ Graduado em Licenciatura e Bacharelado em Ciências Sociais pela Universidade Estadual do Oeste do Paraná (UNIOESTE) e Mestrando no Programa de Pós-Graduação em Ciências Sociais — UNIOESTE, campus de Toledo. Contato: alansantos.1609@gmail.com
} 
theory, and from this to understand why his second work of greater relevance was overshadowed by almost a century returning to the spotlight only from the 1980s.

Keywords: Darwin; Moral; Contractualism.

\section{INTRODUÇÃO:}

Charles Darwin escreveu uma obra muito pouco conhecida e, segundo alguns pesquisadores contemporâneos, muitas vezes mal interpretada, tanto pelas ciências humanas como nas ciências naturais. The Descent of Man, and Selection in Relation to Sex (A Descendência do Homem e Seleção em Relação ao Sexo ou A Origemdo Homem e a Seleção Sexual) teve sua primeira edição publicada no ano de 1871, doze anos após sua maior publicação: On the Origin of Species (1859). Muito possivelmente por acreditarem que esta seria uma continuação de seu primeiro tratado, aplicando suas ideias da seleção natural em comunidades humanas, (Algo que já vinha sendo feito por outros cientistas após os primeiros anos da publicação de A Origem das Espécies), esta obra foi muito pouco recomendada em academias até finais do século XX. Atualmente a teoria sobre "Origem do homem" é considerada como uma segunda revolução darwiniana. Isso se deve muito aos trabalhos de Patrick Tort, considerado, atualmente, o pesquisador que mais escreveu sobre Darwin, sendo destacado principalmente na criação do Instituto Internacional Charles Darwin em 1998, na França.

A obra citada acima, A Descendência do Homem e Seleção em Relação ao Sexo, ao contrário do que muitos imaginavam, inverte a lógica da seleção natural constatada pelo autor em sua obra anterior. Darwin (2003) em A Oigem das Espécies evidencia que os genes que passarão às gerações seguintes são aqueles que conseguiram melhor se adaptar as condições do meio. Essa seleção ocorreria em dois movimentos: Inter e Intra espécies. No primeiro movimento uma seleção em relação às variedades de espécies, onde as variedades menos aptas a sobreviver são eliminadas do processo. Um segundo movimento ocorre em situações onde uma variedade específica torna-se tão apta que ocorre uma superpopulação. Darwin então trabalha com as limitações da subsistência do meio ecológico: quanto maior a população de uma variedade, mais limitada torna-se o acesso à subsistência do indivíduo até o ponto onde há a necessidade da luta pela sobrevivência, agora não mais entre variedades, mas entre os organismos de uma mesma variedade. Neste processo diminui-se a população da espécie ao tempo que a seleção natural não deixa de atuar na "escolha” do mais apto. 
A ideia que Darwin aplica às variedades de espécies que resumem-se na "luta pela vida" era muito conveniente no contexto de uma jovem economia política liberal europeia. Reforçava muitos dos argumentos fundadores da política moderna sobre a criação do Estado e do direito principalmente, tais como ideias de parte do contratualismo clássico, parafraseando Hobbes (2002, p. 34) “[...] uma guerra de todos contra todos, que é a consequência natural daquele estado [de natureza].”.

A obra A Descendência do Homem e Seleção em Relação ao Sexo, mesmo não ganhando a importância que seu escrito anterior, conforme López (2010), Darwin ponderou que o ser humano não ocupa um espaço privilegiado no mundo vivo, afirmando que a definição da condição humana como portador de características de sociabilidade e criação de caracteres simbólicos de significados, são um dado possibilitado por transformações que o Homo Sapiens passou dentro de uma variedade de espécie em contato com outras formas de variedades. Nota-se aqui a qualidade materialista de seu método, ao negar o "fím último" (divino) em detrimento de um postulado fisicalista.

Superada a refutação ao criacionismo a respeito da criação do homem, Darwin (1974) parte para a elaboração de conceitos que envolvem organização social e interação social. Em um primeiro momento (e para não nos alongarmos nesta introdução), nos interessa sua ideia sobre o que ele concebe como origem da "civilização". Para Darwin, a seleção natural levou os humanos a encontrar na sociabilidade ou como ele denomina, "instinto social", um fim último na qual as regras da seleção natural não seriam tão eficazes quanto o instinto de sociabilidade para a manutenção da espécie. Enquanto que para outras variedades de organismos a "eliminação" por seleção é a regra, para os seres humanos, o altruísmo, a simpatia, o afeto pelos integrantes da mesma espécie mantém os laços de sociabilidade, que por sua vez mantém a sobrevivência da espécie.

Nesse sentido, o tratado de Darwin, A Descendência do Homem, passa ao ostracismo pela dualidade consenso/conveniência. Em primeiro lugar a comunidade científica ocidental pressupôs a aplicabilidade do método darwiniano em "A origem das espécies" sobre a seleção natural em comunidades humanas, mesmo o autor em nenhuma de suas mais de 500 páginas indicar essa possibilidade. Em segundo, elementos que favorecem a manutenção da estrutura política e econômica na obra de 1959 (A Origem das Espécies), como a necessidade de um Estado, um poder soberano, sujeição às leis e a um status quo dominante. 


\section{TIPOLOGIAS DA MORAL NO CONTRATUALISMO CLÁSSICO E NA TEORIA DARWINIANA}

A moral nas teorias contratualistas pode ser concebida como um pilar essencial para o entendimento do surgimento do Estado. Pois é a partir da descrição da natureza humana que Thomas Hobbes (1979), por exemplo, derivou a necessidade da criação de um pacto (ato contratual) que extinguiu o poder comum dos indivíduos e os transferiu para o soberano. E para descrevê-la (a natureza humana), concebeu o Estado de Natureza - este que antecede a criação do contrato - citando como seria o comportamento do homem em um contexto onde não existisse um poder que fosse capaz de impor normas de convívio harmônico. Para Hobbes este estado de relações humanas antes da criação do Estado como poder instituído era inevitavelmente uma luta constante entre os indivíduos, todos buscando sempre aumentar seu poder, opondo-se aos demais objetivando ultrapassá-los afim da autopreservação.

Em John Locke (1998), o Estado de Natureza pressupõe uma condição de liberdade e igualdade, porém a falta do Estado não torna tal condição sinônimo dedesordem absoluta. Existem leis naturais, como o direito à vida, integridade e de bens. A alienação a tais direitos por outros sujeitos pressupõe a execução de mecanismos de autopreservação dos próprios sujeitos:

Cada um está obrigado a preservar-se, e não abandonar a sua posição por vontade própria; logo, pela mesma razão, quando sua própria preservação não estiver em jogo, cada um deve, tanto quanto puder, preservar o resto da humanidade, e não pode, a não ser que seja para fazer justiça a um infrator, tirar ou prejudicar a vida ou o que favorece a preservação da vida, liberdade, integridade ou bens de outrem (LOCKE, 1998, p. 385).

Locke assinala então a existência de leis já no Estado de Natureza, o que remete ao poder de execução destas, porém este poder de execução está ligado apenas ao poder de executar as leis naturais, reprimindo injustiças proporcionalmente às agressões, nada além disto.

Jean-Jacques Rousseau (1978) concebe a condição do homem no Estado de Natureza a partir de sua relação com o meio e a inexistência de agrupamentos humanos significativos o que levaria estes a uma vida reclusa. A inexistência de relações de sociabilidade sólidas de comunidade impediu o homem, neste estado (de natureza), de criar, reproduzir ou assimilar valores, como o desejo por riquezas, segurança, poder ou reputação (valores destacados por Hobbes sobre o homem do Estado de Natureza que o levaria a um estado de guerra 
permanente). Nesse sentido, a sociedade civil como superação do Estado de Natureza, só foi possível com o desenvolvimento de tecnologias que possibilitaram um uso mais eficiente da natureza melhorando suas condições de sobrevivência, o que concomitantemente induziu o aumento populacional, ao sedentarismo, a constituição de famílias, o compartilhamento de habitações e a consequente divisão sexual do trabalho:

Nesse novo estado, tendo uma vida simples e solitária, necessidades muito limitadas e os instrumentos que haviam inventado para satisfazê-las, os homens, desfrutando um grande lazer, empregaram-no para obter vários tipos de comodidades desconhecidas de seus pais; e foi esse o primeiro jugo que impensadamente se impuseram e a primeira fonte de males que prepararam para seus descendentes, pois, além de continuarem assim a enfraquecer o corpo e o espírito, ao se habituarem com essas comodidades, estas perderam quase todo o atrativo e ao mesmo tempo degeneraram em verdadeiras necessidades. Assim, a privação delas tornou-se mais cruel do que doce era a sua posse, e sentiam-se infelizes por perdê-las, sem serem felizes por possuí-las (ROUSSEAU, 1978 p. 186).

Assim Rousseau demonstra o processo que levou o ser humano à constituição da sociedade civil. A associação em sociedades organizadas em instituições, ou mesmo no estabelecimento de alianças comerciais, até mesmo amizades, tudo torna-se imprescindível para o desenvolvimento progressivo da capacidade de subsistência, melhorando cada vez mais o bem-estar dos indivíduos.

No contratualismo, o homem é desvinculado do pano de fundo de uma evolução no sentido naturalista, o que levam esses autores a conceber um indivíduo que só pode existir em um estágio mais avançado da história humana, ou seja, o indivíduo contratualista é social, econômico e juridicamente constituído, porém é eurístico, carecendo de uma perspectiva histórica aprofundada. E para além disso, o contratualismo enquanto teoria moral desvincula o indivíduo tanto de seu cenário de origem, a natureza, como a de sua condição inata, ser biologicamente evolutivo, alienando as condições que permitiram ao Homo Sapiens de obter supremacia frente as outras variedades de espécies, como também em face as adversidades naturais que os ameaçaram no meio do caminho. Elementos esses que, conforme a teoria darwiniana, possivelmente contribuíram para a formação de estruturas morais já muito complexas.

\section{OS FUNDAMENTOS DA MORAL HUMANA EMDARWIN}

$\mathrm{Na}$ teoria contratualista, o indivíduo pode ser concebido fora do grupo e, consequentemente, seus interesses pensados como autônomos em relação aos interesses 
grupais. A moral como constituição de formas elementares de relações sociais, então, apresenta-se como um epifenômeno que coaduna com os interesses individuais, estabelecendo um hiato entre este e os interesses grupais (pelo esforço de análise racional das vantagens) (BRITO, 2012).

A constituição da moral humana em Darwin (1974) está ligada diretamente ao fim da seleção natural aplicada aos humanos, e a substituição desta pelos "instintos sociais". Esses instintos são responsáveis por "elevar" o Homo Sapiens à categoria de ser humano, capaz de racionalizar suas ações, sacrificar-se, estabelecer vínculos afetivos, solidariedade, etc.. Tais instintos permitiram, progressivamente, ao funcionamento eliminatório (seleção natural) tornar-se antieliminatório, desenvolvendo as condutas citadas acima. Neste caminho, Patrick Tort (2010, p.82) afirma que:

[...] pela operação da seleção dos instintos sociais e de toda sua constelação de correlatos racionais e afetivos, a seleção natural seleciona a civilização, que se opõe à seleção natural. A vantagem selecionada se torna, então, social. Sem rupturas, a seleção natural, aplicando a si mesma sua própria lei de perecimento das formas antigas, produziu, assim, um efeito de ruptura que legitima a existência distinta de ciências do homem e da sociedade sem recortá-las, à maneira teológica, de suas raízes naturalistas.

Ou seja, por suas próprias regras, a seleção natural, tornou-se menos efetiva e desaparece, tendo o homem encontrado nos instintos sociais um meio mais eficaz para a manutenção e proliferação de sua espécie:

A pouca força e velocidade do homem, sua carência de armas naturais etc. são mais do que contrabalançadas, em primeiro lugar, por suas faculdades intelectuais [que, em outro momento, Darwin diz terem sido conquistadas em sua maior parte, ou mesmo exclusivamente, para o benefício da comunidade] e, em segundo lugar, por suas qualidades sociais, as quais o levaram a dar e receber ajuda de seus companheiros (DARWIN, 2004, p. 63-64) (Grifo nosso).

Neste ponto, a antropologia política de Darwin (1974), apresenta-nos duas concepções complementares do homem. O Homem Selvagem e o Homem Civilizado. Estas concepções referem-se a estágios evolutivos biológicos e não a estágios sociais. É comum, mesmo atualmente, observarmos pesquisadores transferindo estes aspectos de ordem biológica para o campo social, atribuindo a Darwin influências do contratualismo: 
Hobbes (1651) gerou David Hume (1739), que gerou Adam Smith (1776), que gerou Thomas Robert Malthus (1798), que gerou Charles Darwin (1859). Foi depois de ler Malthus que Darwin deixou de pensar sobre competição entre grupos e passou a pensar sobre competição entre indivíduos... O diagnóstico hobbesiano embora não a receita - ainda está no centro tanto da economia quanto da biologia evolutiva moderna (... Darwin gerou Dawkins) (RIDLEY, 2006, p. 284).

Sobre a questão, Kropotkin (2009, p. 73) contrapõe:

[...] ultimamente surgiu uma tendência que, adotando a terminologia de Darwin, e não suas ideias principais, construiu um argumento em favor da visão de Hobbes sobre o homem primitivo e conseguiu até mesmo dar-lhe uma aparência científica. [...] Mais de uma vez disseram que o principal erro de Hobbes, e também dos filósofos do século 18, foi supor que, em seu início, a humanidade vivia sob a forma de pequenas famílias esparsas, algo semelhante às famílias "limitadas e temporárias" dos grandes carnívoros; na realidade, sabe-se agora que não foi esse o caso, longe disso.

Como se sabe, Thomas Henry Huxley (1825-1895) foi o fundador de uma escola que adaptou, convenientemente, a teoria de Darwin sobre a Origem das Espécies à justificativa hobbesiana sobre a constituição do Estado moderno e a constituição da natureza humana:

Num artigo escrito em 1888, ele representou os homens primitivos como se fossem tigres ou leões, destituídos de quaisquer concepções éticas, levando a luta pela sobrevivência a seu mais amargo fim e vivendo uma "contínua luta livre". Segundo ele, "além das relações limitadas e temporárias da família, a guerra hobbesiana de cada um contra todos era a condição normal da vida.” (KROPOTKIN, 2009, p. 73).

Para Darwin (1974), mais do que o desenvolvimento das faculdades morais, os instintos sociais desenvolveram na humanidade a capacidade de "Ajuda Mútua" (conceito desenvolvido mais acentuadamente na corrente sociológica subjetivista sob o naturalismo darwiniano, onde encontra-se maior expoência em trabalhos de Espinas [1877], Kessler [1880], e Kropotkin [1902]), capazes de conferir um estatuto civilizatório à condição humana que encontrava-se em estado selvagem (sob o jugo da seleção natural). É possível perceber, portanto, que a dualidade selvagem/civilizado, não é delimitada pela formação do Estado moderno, sendo para o naturalista, a civilização um "conjunto de princípios, leis e instituições que derivam dessa seleção de instintos sociais" (TORT, 2010, p. 82). Podemos inferir que tais relações são independentes de contratos hipotéticos. Enquanto que para o contratualismo clássico, o Estado inaugura a sociedade civil e a partir desta, a civilização, para Darwin o Estado é apenas fruto de relações provenientes dos instintos sociais que por si só são aspectos civilizatórios anteriores ao Estado.

Em resumo, contra a expectativa da maioria dos políticos e filósofos que leram "A origem das Espécies" e tentavam encontrar nesta a compreensão dos problemas humanos, 
onde compreendiam que as capacidades racionais foram originadas de vantagens adaptativas mais desenvolvidas, decepcionaram-se. Pois o que se constatou foi que o lugar no mundo a qual o homem ocupa, é apenas uma mera extensão homogênea do mundo de todos os outros organismos vivos, não só o indivíduo, mas a moral, nada mais é do que um dado biológico.

\section{A ASSIMILAÇÃO DO DARWINISMO PELAS CIÊNCIAS HUMANAS}

Neste último item reservo-me a comentar sobre essa aventura da biologia num campo, a época, estritamente político-filosófico. Em grande medida, isso se deve pelo fascínio da filosofia política na recepção da obra mais conhecida de Darwin, A Origem das Espécies. Tal fascínio foi mediado muito mais pela conveniência do uso do método do economista Thomas R. Malthus ${ }^{2}$, que sugeriu que a causa da miséria humana seria um descompasso entre o crescimento das populações e a produção de alimentos e que Darwin utilizou como pano de fundo para demonstrar esse fenômeno no mundo animal e vegetal a partir do que denominou de "seleção natural". A utilização do princípio malthusiano foi a força motriz que levou a criação de inúmeras correntes de pensamento a utilizar a teoria da seleção natural em análises sobre comunidades humanas. Como podemos perceber, a "invasão" da biologia na filosofia política não foi à fórceps, de fora para dentro, mas sim um movimento articulado dentro das próprias ciências humanas.

A aproximação entre o darwinismo e a política, deve-se, portanto pela aplicação das leis de Malthus à natureza, ou seja, a aplicação de uma teoria econômica e política à natureza. O que levou a obra de Darwin a ter um papel metafísico dentro das discussões sobre a moral e a natureza humana.

É muito marcante que sua obra direcionada sobre a origem dos instintos sociais humanos ("A descendência do Homem e a Seleção em Relação ao Sexo" [1871]) foi tão amplamente ignorada por quase um século. Certamente a afirmação de que as comunidades que possuíam membros mais cooperativos se desenvolveriam mais e produziriam mais descendentes não foi bem assimilada em uma sociedade marcadamente influenciada pelas teorias contratualistas e seus herdeiros economistas, como David Ricardo e Adam Smith. Neste sentido é emblemática a observação de Kropotikin (2009, p. 21):

\footnotetext{
2 T. R. M. “Um ensaio sobre o princípio da população”, 1803.
} 
Aconteceu com a teoria de Darwin o que sempre acontece com teorias que exercem qualquer influência sobre as relações humanas. Em vez de ampliá-la de acordo com suas próprias intuições, seus seguidores a estreitaram ainda mais. E, embora Herbert Spencer, partindo de linhas de raciocínio independentes, mas intimamente relacionadas com as darwinianas, tentasse ampliar o estudo daquela grande pergunta, "Quem são os mais aptos?", principalmente no apêndice à terceira edição de The Data of Ethics, os inumeráveis seguidores de Darwin reduziram a noção de luta pela sobrevivência a seus limites mais estreitos. Estes acabaram por conceber o mundo animal como um mundo de perpétua luta entre indivíduos semifamintos e sedentos do sangue uns dos outros. Fizeram a literatura moderna ressoar com o grito de guerra de "ai dos vencidos", como se esta fosse a última palavra da biologia moderna. Elevaram a luta impiedosa por vantagens pessoais à condição de um princípio biológico ao qual também o homem deve se submeter, sob a ameaça de, caso contrário, sucumbir em um mundo baseado no extermínio mútuo. Deixando de lado os economistas, cujo conhecimento da ciência natural se resume a umas poucas palavras de segunda mão, devemos reconhecer que mesmo os mais respeitados defensores do ponto de vista de Darwin se empenharam ao máximo para preservar aquelas falsas ideias [referindo-se à T. R. Huxley] (Grifos do autor).

Não se pode negar que Darwin também tem responsabilidade sobre as interpretações tendenciosas de sua principal obra. Furtou-se a desmentir os mal entendidos e divergências levantadas pelos darwinistas sociais apontadas nesta breve reflexão. Afirmou em 1872 que Herbert Spencer ${ }^{3}$ (1864) seria o continuador de sua teoria da evolução. Afirmou que Ernst Haecke ${ }^{4}$ teria em mãos uma nova organização de sistemas orgânicos que substituiria a de Carolus Linnaeus (Carlos Lineu).

Atualmente (A partir da década de 1980), no ocidente, é possível observar a aparição de um "novo Darwin" pelos destaques de releituras de obras como "Ajuda mutua: um fator de evolução" (1903) do supracitado Piotr Kropotkin que influenciou a criação de uma linha de pensamento sociológica subjetiva naturalista, formalmente denominada de sociobiologia (DÓRIA, 2007), tendo seus maiores expoentes Patrick Tort (2010), Ivette Conry (1974), James Allen Rogers (1972) (influenciado por Gabriel Tarde), Humberto Muturana (1995), (1996), (2001a) e (2001b), Muturana e Varela (1996) e (2001), dentre outros.

\section{CONSIDERAÇÕES FINAIS}

Nas comunidades humanas quando o homem passa a viver em sociedade, um novo fenômeno desenvolve-se quando doentes, crianças e idosos, menos aptos em geral, passam a ser protegidos e não eliminados. A este fenômeno Darwin denomina de "civilização".

\footnotetext{
${ }^{3}$ Autor da expressão "sobrevivência do mais apto".

${ }^{4}$ Autor de "Morfologia Geral" (1886), na qual aplicava as conclusões darwinianas sob uma ótica universal
} 
Em contraposição à teoria contratualista, principalmente a linha hobbesiana, da origem das sociedades organizadas e das faculdades morais, Darwin lança um novo olhar sobre as formas elementares do convívio primitivo em Descent of man. Porém este novo olhar é ofuscado por sua obra anterior de mais destaque, "Sobre a Origem das Espécies", que embora não aplique suas conclusões sobre a organização social do homem, é assim interpretada pelas ciências humanas ocidentais oitocentistas.

Este tema levanta uma questão de suma importância para a filosofia e a política da atualidade: até que ponto a constituição biológica interfere na construção da ordem moral?

O que podemos considerar, por fim, é que, por mais que as teorias contratualistas clássicas estejam presentes (resgatando a natureza humana em Hobbes) até nos dias atuais sob a forma de justificativas para manutenção de um sistema econômico degradante tanto para a natureza física como para a natureza do homem na perspetiva darwiniana (predisposição inata à sociabilidade), como também em normas de conduta formais (estreitadas pelos direitos naturais em Locke) em sua forma jurídica, não são suficientes para explicar os assentamentos da moral humana.

Por outro lado, o mau uso feito pelas ciências humanas do biologismo darwiniano, o que chamamos de darwinismo social, também desgastou uma possibilidade de cooperação madura entre as áreas para um melhor entendimento desse fenômeno.

O que se espera é que os novos esforços de resgaste de uma teoria darwiniana consciente, que vem alçando voos moderados atualmente, tenham melhor sorte que as tentativas anteriores.

\section{REFERÊNCIAS}

BRITO, Adriano Naves de. Ecos de Darwin. Ed: UNISINOS. 2012.

CONRY, Y. L'Introduction Du Darwinisme En France Au Xixe Siecle. Paris. Ed. Vrin. 480 p.. 1974.

DARWIN, C. A origem das Espécies. LELLO \& IRMÃO - EDITORES. Porto Alegre. 2003.

A origem do homem e a seleção sexual. Tradução de Attílio Cancian e Eduardo Nunes Fonseca. São Paulo, Hemus Livraria Editora, 715 p. 1974. 
DÓRIA, C. A. Um outro Darwin. In: Evolução Darwiniana e Ciências Sociais. IEA/USP. São Paulo. 2007.

ESPINAS, A. Des sociétés animales. (1877) Ed: Library Félix Alcan.

HAECKEL, E. Generelle Morphologie der Organismen: Allgemeine Grundzüge der organischen Formen-Wissenschaft, mechanisch Begründet durch die von Charles Darwin reformirte Descendenz-Theorie. Ed. Georg Reimer. Berlim, 1866.

HOBBES, Thomas. Do cidadão. 3. ed. Tradução de Janine Ribeiro. São Paulo: Martins fontes, 2002. Original inglês. (Clássicos).

Leviatã ou matéria, forma e poder de um estado eclesiástico e civil. Tradução de João Paulo Monteiro e Maria Beatriz Nizza da Silva. 2. ed. São Paulo: Abril Cultural, 1979. (Os Pensadores).

KESSLER, K. F. The zakone, p. 136 e 127 (Sobre a Lei de Auxílio Mútuo, em Memoirs of the Society of Naturalists of St. Petersburg,Vol. XI, 1880)

KROPOTKIN, P. Ajuda mútua: um fator de evolução. Tradução: Waldyr Azevedo Jr. São Sebastião: A Senhora Editora, 2009.

LOCKE, John. Dois tratados sobre o governo. São Paulo: Martins Fontes, 1998.

LÓPEZ, M. As implicações materialistas da teoria de Darwin. Revista: Medicina y Humanidades v2, no 08.2010.

MATURANA, H. R. Cognição, ciência e vida cotidiana. Belo Horizonte: Editora da UFMG, 2001a. 200 p.

La realidad ¿objetiva o construida?: I fundamentos biológicos de la realidad. México: Anthoropos, 1995.

La realidad ¿objetiva o construida? II fundamentos biológicos del conocimiento. México: Anthoropos, 1996.

A ontologia da realidade. Belo Horizonte: Editora da UFMG, 2001b. 350p.

MATURANA, H. R. \& VARELA, F. El árbol del conocimiento: las bases biológicas del conocimiento humano. Madrid: Debate, 1996.

A árvore do conhecimento: as bases biológicas da compreensão humana. São Paulo: Palas Athena, 2001. 283 p.

RIDLEY, M. Evolução. Porto Alegre: Editora: Artmed, 2006.

ROGERS, J. A."Darwinism and Social Darwinism," Ed: Journal Hist. Ideas, Pennsylvania. 1972. 
ROUSSEAU, Jean-Jacques. Do contrato social [1762]; Ensaio sobre a origem das línguas. 2a. ed.. São Paulo: Abril Cultural (Col. Os Pensadores), 1978.

SPENCER, H. Principles of Biology. London: Williams and Norgate, 1864.

TORT. P. Sobre Darwin: Entrevista com Patrick Tort. Revista: Crítica Marxista, n.30, p.7987, 2010. 